The Rangeland Journal, 2013, 35, 193-200

http://dx.doi.org/10.1071/RJ12084

\title{
Scaling results up from a plot and paddock scale to a property - a case study from a long-term grazing experiment in northern Australia
}

\author{
J. C. Scanlan ${ }^{\mathrm{A}, \mathrm{D}}$, N. D. MacLeod ${ }^{\mathrm{B}}$ and P. J. O' Reagain ${ }^{\mathrm{C}}$ \\ ADepartment of Agriculture, Fisheries and Forestry, Toowoomba, Qld 4350, Australia. \\ ${ }^{\mathrm{B} C S I R O}$ Ecosystem Sciences, Dutton Park, Qld 4102, Australia. \\ ${ }^{\mathrm{C}}$ Department of Agriculture, Fisheries and Forestry, Charters Towers, Qld 4820, Australia. \\ DCorresponding author. Email: joe.scanlan@daff.qld.gov.au
}

\begin{abstract}
Grazing experiments are usually used to quantify and demonstrate the biophysical impact of grazing strategies, with the Wambiana grazing experiment being one of the longest running such experiments in northern Australia. Previous economic analyses of this experiment suggest that there is a major advantage in stocking at a fixed, moderate stocking rate or in using decision rules allowing flexible stocking to match available feed supply. The present study developed and applied a modelling procedure to use data collected at the small plot, land type and paddock scales at the experimental site to simulate the property-level implications of a range of stocking rates for a breeding-finishing cattle enterprise. The greatest economic performance was achieved at a moderate stocking rate of 10.5 adult equivalents $100 \mathrm{ha}^{-1}$. For the same stocking rate over time, the fixed stocking strategy gave a greater economic performance than strategies that involved moderate changes to stocking rates each year in response to feed supply. Model outcomes were consistent with previous economic analyses using experimental data. Further modelling of the experimental data is warranted and similar analyses could be applied to other major grazing experiments to allow the scaling of results to greater scales.
\end{abstract}

Additional keywords: cattle grazing, economics of resource use, grazing management, modelling, scaling-up.

Received 22 October 2012, accepted 9 April 2013, published online 6 May 2013

\section{Introduction}

Stocking rate is the key management factor determining pasture condition, livestock production and economic performance on rangelands (O'Reagain and Turner 1992; Danckwerts et al. 1993). Accordingly, grazing experiments have been widely used to assess appropriate stocking rates for different regions. In Northern Australia, for example, grazing experiments have been conducted in southern Queensland (Scattini 1973), central Queensland (Burrows et al. 2010), northern Queensland (Gillard 1979) and the Northern Territory (Cowley et al. 2007). More recently, the Wambiana experiment in north Queensland has compared the relative performance of different stocking strategies in managing for climate variability (O'Reagain et al. 2009). The latter results are of particular significance as they provide empirical evidence showing that strategies, such as moderate or flexible stocking rates, are not only more sustainable but just as profitable as higher stocking-rate strategies (O'Reagain et al. 2011).

Despite their value, grazing experiments are expensive and extrapolation of results to other land types, climate sequences or management systems requires caution. Extrapolation to the property level is particularly problematic. First, this is due to differences in the spatial scale and heterogeneity of experimental paddocks and commercial properties and second, the uncertainty associated with translating livestock production relationships derived from one category of livestock to another, e.g. steers to breeding cattle (Ash and Stafford Smith 1996). These are important issues which may limit adoption of better management strategies by the grazing industry.

Simulation modelling has been suggested as a tool to allow extrapolation of the results of grazing experiments in time and space. For example, Foran and Stafford Smith (1991) tested the economic performance of constant average or low stocking rates against a high, variable stocking-rate strategy. They reported that accumulated cash surpluses over 100 years were lower for low than for high stocking rates but the former showed less year-to-year variation. In their simulations, properties with low stocking rates would have avoided bankruptcy during the dry period from 1956 to 1965 whereas the properties with high stocking rates would not have (Foran and Stafford Smith 1991). The major benefit of a low stocking rate was that livestock production was maintained in dry years (Buxton and Stafford Smith 1996). A limitation of these simulations is that the negative effects of high stocking rates on rangeland condition 
and its impact on subsequent livestock production could not be assessed [see O'Reagain and Scanlan (2013) for discussion of issues in northern Australia].

GRASP, a point-based, biophysical model, has been used extensively to estimate long-term carrying capacity across many regions of northern Australia (McKeon et al. 2009) and to predict the impacts of different stocking rates on perennial grasses, livestock production and soil loss (e.g. Ash et al. 2000; McKeon et al. 2000). However, these studies involved non-breeding livestock, making extrapolation to commercial situations with breeding livestock difficult. Further, the response of pasture condition to grazing pressure was calculated from pasture utilisation rates over the entire year, whereas evidence indicates that pasture condition is disproportionately sensitive to early wet-season utilisation rates (e.g. Ash et al. 2011).

Recent modifications to GRASP have enabled the negative impacts of grazing strategies on pasture condition to be more accurately modelled (Pahl et al. 2011; Scanlan et al. 2011). Simulation results from GRASP have recently been coupled with a dynamic herd model (ENTERPRISE - MacLeod and Ash 2001), and used to examine the property-level implications of different grazing management strategies for a breedingfinishing business (MacLeod et al. 2011).

This paper aims to demonstrate how detailed plant and animal data collected at the plot and paddock level in grazing experiments can be applied at a property level and linked to an economic model to assess the potential impacts of different stocking-rate strategies. Data drawn from the Wambiana grazing experiment(O'Reagain et al. 2009; P. J. O'Reagain, unpubl. data) are used in this case study.

\section{Methods}

The Wambiana grazing experiment $\left(20^{\circ} 34^{\prime} \mathrm{S}, 146^{\circ} 07^{\prime} \mathrm{E}\right)$ was established in 1997, $70 \mathrm{~km} \mathrm{SW}$ of Charters Towers, north Queensland. Mean long-term annual rainfall (July-June) for the site is $\sim 640 \mathrm{~mm}$ but is highly variable with rainfall over the period of the experiment varying from $380 \mathrm{~mm}(2001-02)$ to $1232 \mathrm{~mm}$ (2010-11). The site is an open eucalypt woodland with the dominant $(\sim 55 \%)$ land type being Reid river box (Eucalyptus brownii Maiden \& Cambage) on grey-brown sodosols; there are significant areas of Ironbark (E. melanophloia F. Muell.) and Brigalow (Acacia harpophylla F. Muell. Ex Benth.). There are 10 experimental paddocks of 93-117 ha, with two blocks of five grazing strategies (O'Reagain et al. 2009). Strategies tested were a moderate stocking rate of steers at the estimated long-term carrying capacity (LTCC) of 12.5 adult equivalents (AE) $100 \mathrm{ha}^{-1}$ $(\mathrm{AE}=450 \mathrm{~kg}$ steer $)$ and a high stocking rate at twice the LTCC, i.e. $25 \mathrm{AE} 100 \mathrm{ha}^{-1}$. Although these treatments are referred to as fixed, there was a small amount of year-to-year variation; this was less than a $10 \%$ change from year to year. Two variable stocking strategies, as well as a rotational wet season spelling strategy, were also tested (O'Reagain et al. 2009). In the variable stocking strategies, numbers of steers were adjusted annually based upon forage availability either (a) at the end of the wet season (May) or (b) in October/November and a seasonal climate forecast for the coming wet season based on the
Southern Oscillation Index. Individual annual liveweight gain (LWG) data were collected for all steers in all paddocks from 1998 to 2011. If there were changes to numbers of steers in paddocks, this was done in June after the end of the growing season. In one of the paddocks on the high stocking-rate treatment, steers had to be removed for 4 months in 2004 due to feed shortages (see O'Reagain et al. 2009; for further details).

Pasture data were collected at two spatial scales. First, detailed data were collected over seven growing seasons (from September 1998 to June 2005$)$ on replicated small $(30 \times 30 \mathrm{~m})$ plots within the box land type using the methodology of Day and Philp (1997) to enable parameterisation of the GRASP pasture production model. (The GRASP model was initially developed for sub-coastal grasslands in Queensland, which are similar to the pastures within the experiment). Second, the herbage mass of dry matter (TSDM) was measured and species composition data were collected twice per year from 1998 to 2011 at the land type as well as at the whole paddock level using the BOTANAL procedure (Tothill et al. 1992). The observed data for $3 \mathrm{P}^{1}$ grasses were used to compare with the modelled percentage of perennial grasses. Within GRASP, the simulated percentage of perennial grasses is used as an index of potential productivity, rather than to estimate the actual pasture composition of perennial grasses. The maximum pasture productivity is achieved at $90 \%$ perennial grasses and the minimum pasture productivity at $1 \%$ perennial grasses. It is not appropriate to compare simulated perennial grasses with the observed sum of all perennial grasses (e.g. 3P added to $2 \mathrm{P}$ grasses): this would overestimate the productive potential of a pasture in which $2 \mathrm{P}$ grasses were a large proportion of the total perennials as $3 \mathrm{P}$ grasses are the most productive grasses in the pasture.

The analytical schema shown in Fig. 1 indicates how the data, collected at the plot and paddock level, were linked to provide economic performance results at the property level. The first step in analysing the field data was to calibrate the GRASP model for the box land type to provide suitable parameters for running the GRASP model for further simulations. This was done according to the procedure initially outlined by Scanlan et al. (2008). A simplifying assumption used in this study was that all paddocks could be represented by the box land type, even though two other major land types were present in each paddock, and made up $\sim 45 \%$ of the experimental area. The GRASP model was run over the experimental period from 1998 to 2011 with the results compared with field data for TSDM and LWG of steers at the scale of the paddock. The annual period of simulation was from 1 June to 31 May of the following year, to coincide with the changeover of steers within the experiment and to capture a complete rainy season within each annual simulation period.

Some calibration of the parameters which drive the change in the percentage of perennial grasses in the pasture was needed, as these parameters could not be derived from the small plot data. Within GRASP, the percentage of perennial grasses is a non-linear function of pasture 'state' with state 0 having $90 \%$ perennial grass and state 11 having $1 \%$ perennial

\footnotetext{
${ }^{1} 3 \mathrm{P}$ grasses are perennial, productive and preferred; $2 \mathrm{P}$ grasses have only two of these characteristics.
} 


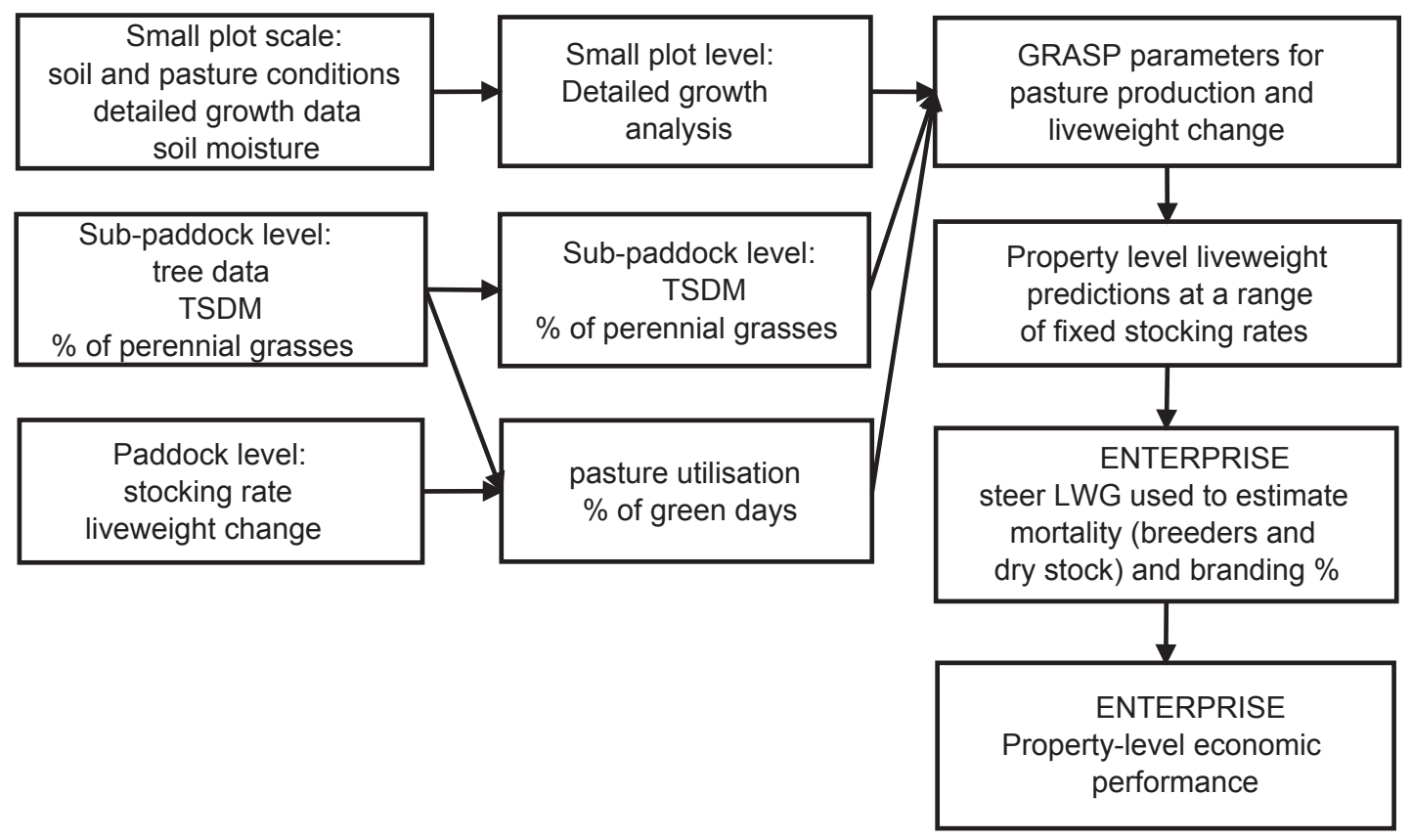

Fig. 1. Key steps in evaluating the effect of stocking rate on property-level biophysical and economic performance (LWG, liveweight gain; TSDM, herbage mass of dry matter).

grasses (see fig. 1 in McKeon et al. 2000). If pasture utilisation is higher than the specified safe utilisation level for that pasture type, pasture state deteriorates; if pasture utilisation is lower than the safe utilisation, then pasture state improves. The annual improvement in state at zero utilisation was set to 0.65 and the annual rate of deterioration in state at $100 \%$ utilisation was set to 0.75 . Within $\sim 10 \%$ of the safe utilisation, the change in state occurs at a lower rate than at higher or lower utilisation rates. Parameter 646 is the change in state at this point of change from the lower to higher rates and is set to 0.15 (see fig. $1 b$ in Scanlan et al. 2011; for further information). No alteration to the growth parameters, estimated from the small plots, was made.

Simulations were then run for all paddocks to estimate annual pasture utilisation rates and the percentage of green days in the year (days when the growth index exceeded 0.05) using paddock stocking rates and rainfall records. Pasture utilisation rates and the percentage of green days were then used as inputs into the general equation to estimate annual LWG of steers. This equation is based on data from Gayndah, Calliope and Kangaroo Hills in Queensland [see McKeon et al. (2000) and eqn 1 in Mayer et al. (2011) for more details of the calculations of LWG]. The only modification required to provide a good fit to the observed annual LWG data in the Wambiana grazing experiment was a reduction in the intercept in the equation from 0.0603 to 0.0270 . Liveweight data for 2004-05 and 2006-07 were excluded from the analysis as some paddocks had additional energy supplementation or were destocked during parts of these years (see O'Reagain et al. 2009; for details).

The ENTERPRISE model, originally developed by MacLeod and Ash (2001), was used to examine property-level economic performance of a breeding-finishing business. A change was made to the original model such that the liveweights of steers that had to be sold due to poor seasonal conditions were reduced. The property was 23500 ha composed of the box land type with $\$ 750000$ debt and $\$ 168500$ annual overhead costs. Steers were sold at $590 \mathrm{~kg}$ liveweight or at 3 years of age and excess females were also sold. Supplementary feeding was initiated if projected annual individual LWG of steers was less than $40 \mathrm{~kg}$.

Within ENTERPRISE, the LWG of steers is used to estimate mortality separately for steers and breeders, as described in MacLeod and McIvor (2004), and is based on the work of Gillard and Moneypenny (1988) in the same region of north Queensland. Specifically, the following mortality and branding rate equations are used within ENTERPRISE:

$$
\begin{aligned}
& \text { Mortality (breeders) } \%=6+94 \mathrm{e}^{-0.027 *[\mathrm{LWG}(\text { steers })+50]} \\
& \text { Mortality (dry stock) } \%=2+88 \mathrm{e}^{-0.034 *[\mathrm{LWG}(\text { steers })+50]} \\
& \text { Branding } \%=0 \leq 15.6+0.488 \mathrm{LWG}(\text { steers }) \leq 80
\end{aligned}
$$

Mayer et al. (2012) suggested that the mortality rates produced by these equations are unrealistically high. However, this resulted from an assumption that the LWG used in the equation for breeders was the LWG of the breeders, rather than the LWG of the steers grazing the same pastures. The equations above produce values which are reasonable for this region.

GRASP simulations were then run to generate percentage of perennial grasses and annual LWG of steers for a 30-year period (beginning of June 1981 until end of May 2011) for three stocking-rate strategies and with a very wide range of initial stocking rates (from 3 to $35 \mathrm{AE} 100 \mathrm{ha}^{-1}$ ). The stocking strategies simulated were: fixed (same livestock numbers each year); low flexibility (numbers were allowed to change by up to $10 \%$ per year at the end of the growing season, beginning of June, in 
response to seasonal conditions); and moderate flexibility (where livestock numbers were allowed to change by up to $40 \%$ per year in June, depending on pasture production). The low flexibility strategy was very similar to the actual year-to-year variation in the 'fixed' stocking rates used in the Wambiana grazing experiment and reflected slightly different starting liveweights and very small differences in the numbers of livestock per paddock. The moderate flexibility simulations reflected the actual year-to-year variation observed in the variable stocking-rate treatments used in the grazing experiment. Initial percentage of perennial grasses for all simulations was $\sim 50 \%$, which was similar to the observed percentage of $3 \mathrm{P}$ grasses at the start of the grazing experiment. Results from these simulations were then used as the input into the ENTERPRISE model for the 30-year simulation period.

The actual climate window used for simulation will impact on the economic and biophysical results of simulations. To examine this impact, four other 30-year (June-May) climate windows were simulated. The 1981-2011 results were compared with the window that produced the overall highest LWG and percentage of perennial grasses (the 1956-86 period).

\section{Results}

Once calibrated for the site, GRASP represented the actual pasture production on the small plots (as represented by TSDM) very well (Fig. 2). Paddock-level pasture production was also well represented by the calibrated GRASP model with the yearto-year variation, due to rainfall, captured (Fig. $3 a$ ); the overall proportion of variation between observed and simulated TSDM explained was 0.82 (Fig. $3 b)^{2}$. In addition, the observed percentage of $3 \mathrm{P}$ grasses on the box land type was represented reasonably well by the percentage of perennial grasses generated by the model (Fig. 4). At least some of the unexplained variation in the data may have been due to some productive perennial grasses not being classified as $3 \mathrm{P}$ grasses. Considering the relatively simple representation of perennial grass composition in GRASP and how it changes, these results are considered to be suitable for use in simulations. This is the first time that recent modifications to GRASP to estimate changes in percentage of

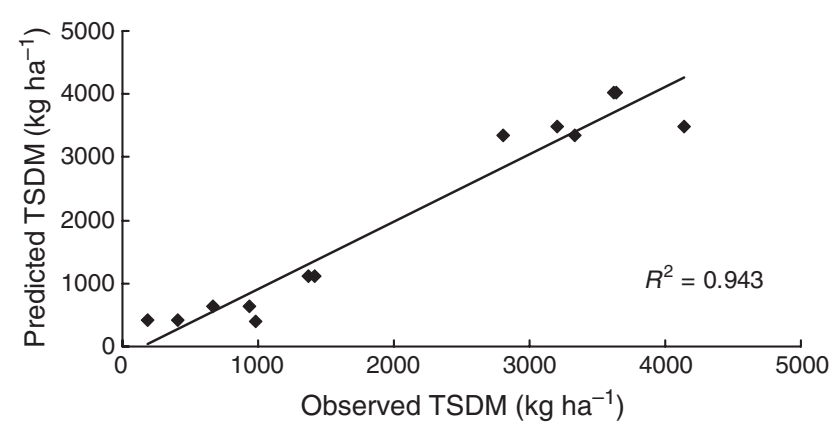

Fig. 2. Observed and predicted herbage mass of dry matter (TSDM) in the small plots in the box land type in the Wambiana grazing experiment, after calibration of the GRASP model. perennial grasses (Scanlan et al. 2011) have been tested extensively against data from grazing experiments.

Predictions of LWG of steers by GRASP captured the pattern of year-to-year variation for individual paddocks (Fig. 5a). Overall, there was a good match between observed and simulated LWG for all paddocks $\left(R^{2}=0.64\right)$ when data from 2 years (2004-05 and 2006-07) were excluded (Fig. 5b). These 2 years were two extreme drought years, with a very low herbage mass $\left(<600 \mathrm{kgDMha}^{-1}\right)$ and one treatment was partially destocked. Examination of the data for these years (in the paddocks that were not destocked) indicated that the percentage of green days was much higher than for comparable LWG in other years and that the level of utilisation was also much higher than for comparable observed LWG. The reason for this requires further investigation.

Estimates of the gross margin (GM) from the ENTERPRISE model tended to remain at $\sim \$ 140-150$ per AE at fixed stocking rates up to $8 \mathrm{AE} 100 \mathrm{ha}^{-1}$ (Fig. 6a), with similar but slightly lower GM for the other strategies, when compared at the same average stocking rates over the 30-year simulation period. Above this stocking rate, $\mathrm{GM} \mathrm{AE}^{-1}$ declined up to the maximum stocking rate simulated. Between average stocking rates of 10 and $15 \mathrm{AE} 100 \mathrm{ha}^{-1}$, the moderate flexibility strategy had a higher $\mathrm{GM} \mathrm{AE}^{-1}$. Above this stocking rate, there was no consistent difference between the fixed and low flexibility strategy. The decline in $\mathrm{GM}$ per $\mathrm{AE}^{-1}$ at stocking rates of above $8 \mathrm{AE} 100 \mathrm{ha}^{-1}$
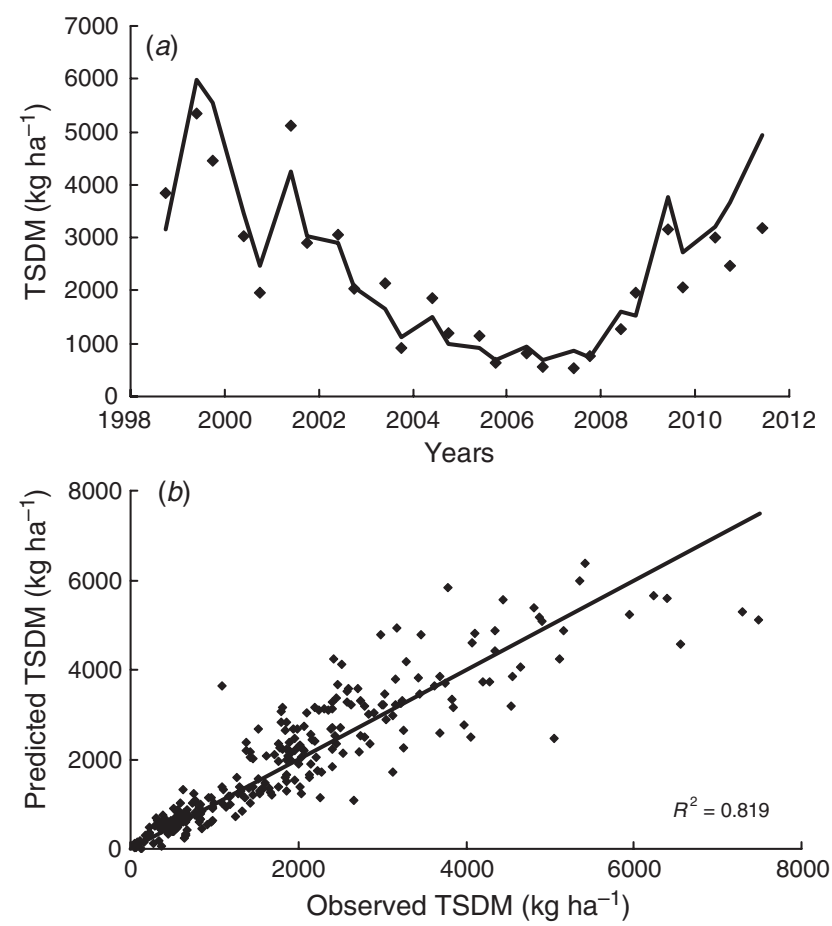

Fig. 3. (a) Predicted ( - ) and observed $(\diamond)$ herbage mass of dry matter (TSDM) for one of the moderate stocking-rate paddocks (paddock 5), and (b) predicted versus observed herbage mass of dry matter (TSDM) for all paddocks at all sampling dates in the Wambiana grazing experiment

${ }^{2}$ In the Figures, paddock 5 is used as an example. Results for other paddocks produced similar results in terms of the goodness of fit. 

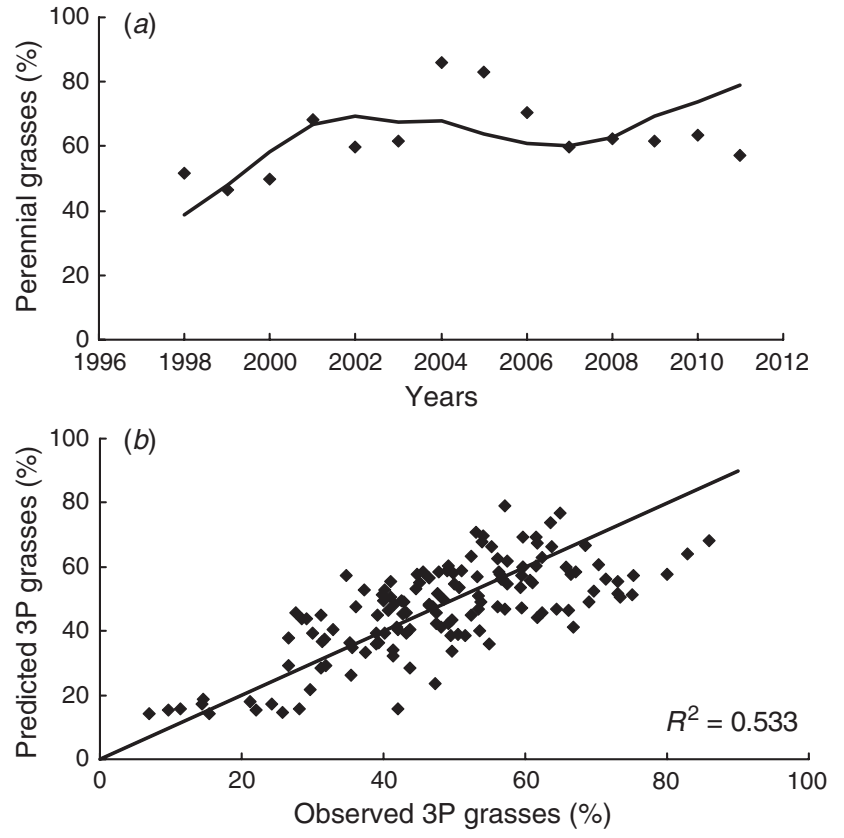

Fig. 4. (a) Predicted percentage of perennial grasses $(\square)$ and observed percentage of $3 \mathrm{P}(\checkmark)$ perennial grasses for one of the moderate stocking-rate paddocks (paddock 5), and (b) predicted percentage of perennial grasses versus observed percentage of $3 \mathrm{P}$ perennial grasses for all paddocks at all sampling dates in the Wambiana grazing experiment.
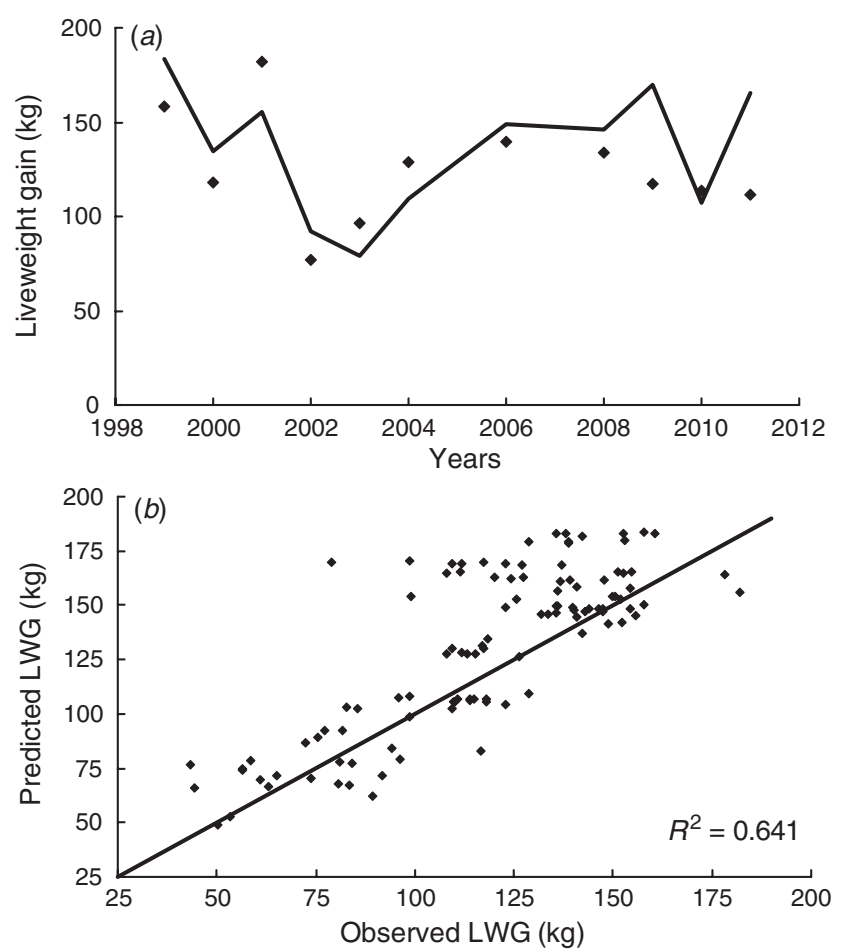

Fig. 5. (a) Predicted $(-)$ and observed $(\bullet)$ individual annual liveweight gain for paddock 5 , and $(b)$ predicted versus observed individual annual liveweight gain for all paddocks for all years except 2004-05 and 2006-07 in the Wambiana grazing experiment.
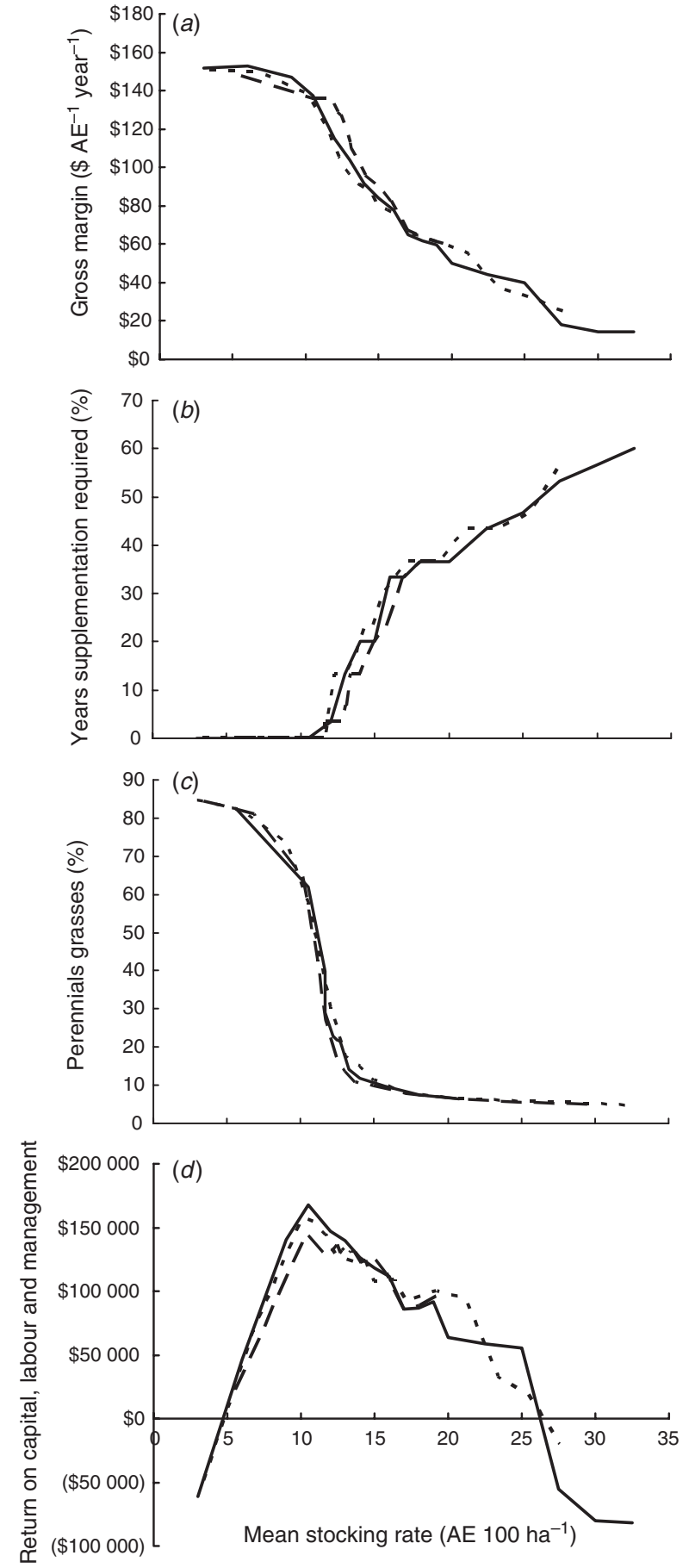

Fig. 6. (a) Gross margin per adult equivalent (AE); (b) percentage of years when supplementary feeding was required due to lack of feed available; $(c)$ percentage of perennial grasses; and $(d)$ return on capital, labour and management from simulation of a range of average stocking rates with fixed (solid line), moderate (dashed) and low flexibility (short dashed) stocking-rate strategies from 1981 to 2011 for a property composed of the box land system. (Note that the stocking rates for the low and moderate flexibility strategies do not extend to the maximum shown for the fixed stocking rate. This is because the model reduced initial stocking rates, which were in excess of carrying capacity so that above a threshold value the mean stocking rate over the 30year simulation period was lower than the initial stocking rate.) 
reflects the decline in individual LWG with increasing stocking rate.

As the stocking rate increased, the percentage of years where supplementation is required (when simulated individual annual LWG of steers was $<40 \mathrm{~kg}$ ) increased (Fig. $6 b$ ). The moderate flexibility strategy required supplementation in a lower percentage of years than the other strategies. This is because the stocking rates are adjusted to more closely match the pasture present than in the other strategies. The simulated percentage of perennial grasses declined sharply for all stocking strategies above $10 \mathrm{AE} 100 \mathrm{ha}^{-1}$ (Fig. 6c). When overheads are deducted, the return on capital, labour and management (net profit) peaked at 10.2-10.5 AE $100 \mathrm{ha}^{-1}$ (Fig. 6d). The decline above this figure was associated with increased supplementary feeding costs and a lower price per head for livestock sold in years when supplementation was required. In addition, the percentage of perennial grasses dropped below the initial level for the simulations ( $\sim 50 \%$ of perennial grasses).

Conditions during the 1956-86 window produced higher LWG of steers and, therefore, lower predicted breeder mortality, and simulated percentages of perennial grasses were higher than the 1981-2011 window (Table 1). Note that the predicted mortality rates for breeders for stocking rates up to $13 \mathrm{AE} 100 \mathrm{ha}^{-1}$ in both simulation periods are similar to those given in table 3 of Mayer et al. (2012) for other models. The LWG of steers in Table 1 would have produced individual annual LWG values for breeders similar to those presented by Mayer et al. (2012) $10-34 \mathrm{~kg}$. Thus, the equations in ENTERPRISE produce realistic mortality rates for this environment.

The 1956-1986 window produced far superior economic performance, particularly at the higher stocking rates, than did the 1981-2011 window. This highlights the over-riding influence of climate on herbage and livestock production, and, therefore, economic performance.

\section{Discussion}

This study has used information collected at several spatial scales to estimate economic performance at a property scale. The three grazing strategies produced a similar economic performance when compared at the same stocking rate for the 30 -year simulation period. Near the optimum stocking rate, the fixed stocking strategy was slightly better than the flexible stocking rates, supporting earlier conclusions by O'Reagain et al. (2011). There were major differences between the 30-year climate windows used for the simulations.

The annual LWG predictions based on parameters derived from other grazing experiments in Queensland (eqn 1 in Mayer et al. 2011) produced a good match between observed and predicted LWG of steers. Nevertheless, further detailed analysis is warranted to determine why the general relationship did not fit the data from the experiment in 2004-05 and 2006-07. In addition, a LWG model with a shorter time step (daily or weekly) is required to evaluate strategies in which more than one decision point is used per year to adjust stocking rates. Initial investigations indicated that a daily model using a similar approach to the annual model is worth investigating and incorporating into the GRASP model for evaluation (Mayer et al. 2011).

Economic analysis of data from the Wambiana experiment (O'Reagain et al. 2011) showed that moderate stocking rates (8-10 AE $100 \mathrm{ha}^{-1}$ ) gave a net present benefit of $\sim \$ 120 \mathrm{ha}^{-1}$, far higher than the \$70/ha under the high stocking-rate treatment $\left(\sim 20 \mathrm{AE} 100 \mathrm{ha}^{-1}\right)$. These values are lower than those presented here: differences are to be expected due to fundamental differences between the two studies. First, the present simulations spanned a 30-year period (1981-2011) whereas the results of the experiment covered only from 1997 to 2011. Second, fixed prices were applied in this study (including for livestock sold in poor condition) and this differed from the actual yearly prices recorded by O'Reagain et al. (2009) and used in their economic analysis of the experiment (O'Reagain et al. (2011). Third, the present study simulated a breeding-finishing enterprise at the property scale compared with the steer-only analysis at the scale of the experiment in O'Reagain et al. (2011). The steer data from the grazing experiment, nevertheless, provide a critical foundation for predicting the performance of breeding cattle under similar management strategies as the ENTERPRISE model uses the potential LWG of steers to estimate the performance and mortality of breeding cattle.

Table 1. Comparison of key economic and biophysical results for two climate windows

1981-2011 was the overall lowest period compared with 1956-86, which was the highest period of the five different 30-year windows simulated

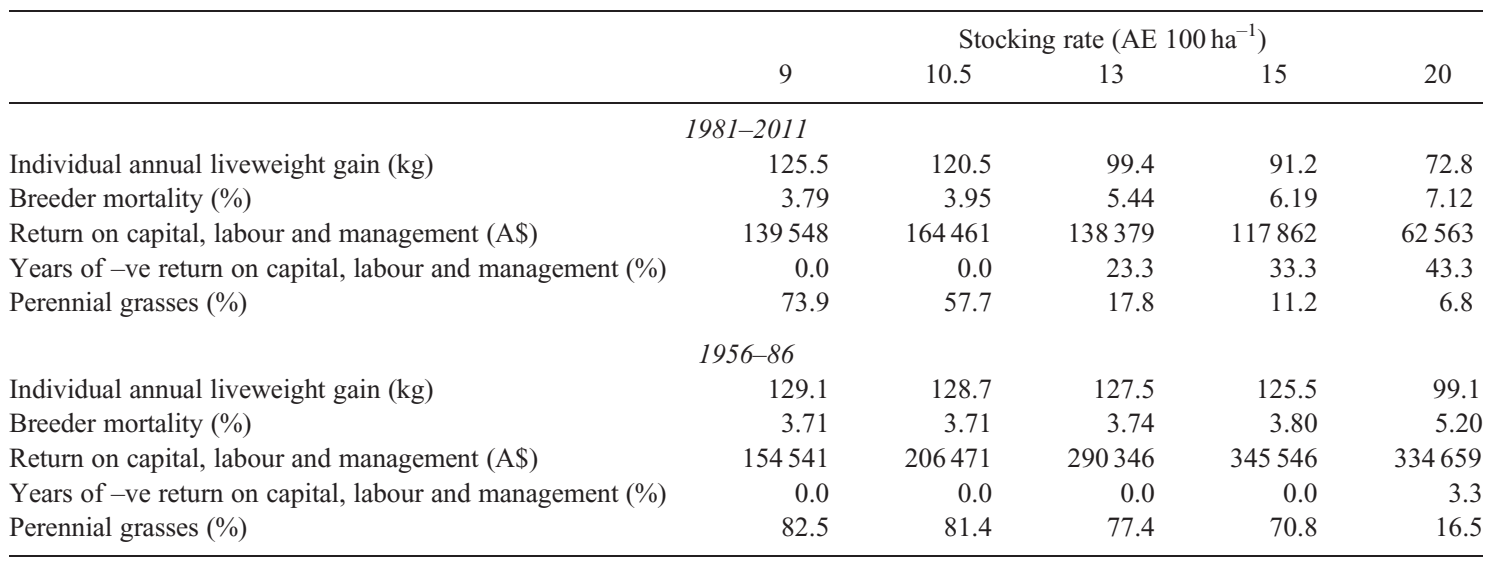


The simulated economic optimum for the three different strategies occurred at $10.5 \mathrm{AE} 100 \mathrm{ha}^{-1}$. At that stocking rate, the simulated composition of $3 \mathrm{P}$ perennial grasses was $\sim 60 \%$, considerably less than the maximum of $90 \%$ of perennial grasses. To ensure that the percentage of perennial grasses remained high through a simulation period, the stocking rate would have to be slightly lower than that which produced the greatest economic performance.

The procedure outlined in this paper shows how experimental data collected at both plot and paddock scales can be used to explore the economic performance of properties. Despite the simplifications made during the analyses, especially assuming all paddocks could be represented by one land type, the fit between predictions and observations at the paddock level was very good for herbage production and annual LWG. This is possibly because the box land type was the most preferred in the Wambiana experiment (P. J. O'Reagain, pers. obs.) and thus potentially had the largest impact on livestock production. Provided the appropriate data were collected, this process could be applied to all grazing experiments as a means of investigating the long-term biophysical effects of individual treatments, as well as scaling results up to the property level. This overcomes three common criticisms/limitations of grazing experiments: that the experiments generally do not run for a long enough period to produce major impacts on pasture condition; that only a limited combination of rainfall years can be experienced and the results may differ given a different climatic sequence; and that the full economic impact can only be assessed if examined at the property level and/or that the outcomes would be different if a different class of livestock, e.g. breeders, had been used.

A major simplification in this study was to assume that a paddock could be represented by the dominant land type, the box land type. This is likely to have a major impact on model outcomes e.g. selective grazing of small areas of more preferred land types could result in serious degradation. Also, spatial heterogeneity of land types/resources in one grazing unit (paddock) can buffer the effects of drought or seasonal nutrient deficits on livestock production. At present, LWG cannot be modelled in a landscape composed of mixed land types. The magnitude of withinpaddock variability effects is not known.

Recent enhancements to GRASP have modified the way in which changes in the percentage of perennial grasses are modelled (Scanlan et al. 2011) and this is the first major study to apply these changes to data from a grazing experiment. Nevertheless, present models of change in perennial grasses in response to management and rainfall are probably simplistic and this area requires further development. Further analyses of other grazing experiments should also be undertaken to provide estimates of the model parameters to represent changes in other locations and land types.

In summary, this paper has shown how data collected at the level of the grazing experiment can be extrapolated upwards to the property scale. Further modelling analyses should be conducted to investigate the potential impact of some of the factors on the results obtained, particularly the influence of mixed land types within properties. In addition, the reasons for the inability of the model to estimate livestock production in 2004-05 and 2006-07 require investigation.

\section{Acknowledgements}

We thank Meat and Livestock Australia for their ongoing funding of the Wambiana experiment and the modelling that made this paper possible. We are grateful to the Lyons family of 'Wambiana' for their interest, guidance and support in running the experiment. John Bushell provided critical technical support and guidance through all stages of the experiment and his key role is gratefully acknowledged. We also gratefully acknowledge the advice, help and support of many other colleagues. Ken Day in particular played a crucial role encouraging the collection of the important pasture production data. Dr Greg McKeon has been an inspiration in pursuing the modelling of grazing experiments.

\section{References}

Ash, A. J., and Stafford Smith, D. M. (1996). Evaluating stocking rate impacts in rangelands: animals don't practice what we preach. The Rangeland Journal 18, 216-243. doi:10.1071/RJ9960216

Ash, A. J., O’Reagain, P. J., McKeon, G., and Stafford Smith, D. M. (2000). Managing climate variability in grazing enterprises: a case study of Dalrymple Shire, north-eastern Australia. In: 'Applications of Seasonal Climate Forecasting in Agricultural and Natural Ecosystems: The Australian Experience'. (Eds G. L. Hammer, N. Nicholls and C. Mitchell.) pp. 253-270. (Kluwer Academic Publishers: Dordrecht, The Netherlands.)

Ash, A. J., McIvor, J., Corfield, J., and Ksiksi, T. (2011). Grazing management in tropical savannas: utilization and rest strategies to manipulate rangeland condition. Rangeland Ecology and Management 64, 223-239. doi:10.2111/REM-D-09-00111.1

Burrows, W. H., Orr, D. M., Hendricksen, R. E., Rutherford, M. T., Myles, D. J., Back, P. V., and Gowen, R. (2010). Impacts of grazing management options on pasture and animal productivity in a Heteropogon contortus (black speargrass) pasture in central Queensland. 4. Animal production. Animal Production Science 50, 284-292. doi:10.1071/AN09145

Buxton, R., and Stafford Smith, M. (1996). Managing drought in Australia's rangelands: four weddings and a funeral. The Rangeland Journal 18, 292-308. doi:10.1071/RJ9960292

Cowley, R. A., McCosker, K. D., MacDonald, R. N., and Hearnden, M. N. (2007). Optimal pasture utilisation rates for sustainable cattle production with a commercial Brahman herd in the Victoria River Downs region of the Northern Territory. In: 'Proceedings of the Northern Beef Research Update Conference'. (Eds B. Pattie and B. Restall.) pp. 34-44. (North Australia Beef Research Council: Townsville, Qld.)

Danckwerts, J. E., O’Reagain, P. J., and O'Connor, T. G. (1993). Range management in a changing environment: a southern African perspective. The Rangeland Journal 15, 133-144. doi:10.1071/RJ9930133

Day, K. A., and Philp, M. W. (1997). SWIFTSYND METHODOLOGY. A methodology for measuring a minimum data set for calibrating pasture and soil parameters of the pasture growth model GRASP Appendix 3 for 'Final Report DAQ124A Evaluating the risks of pasture and land degradation in native pastures in Queensland'. Available at: www. longpaddock.qld.gov.au/grasp/pdf/Swiftsynd_Manual.pdf (accessed 25 March 2013).

Foran, B. D., and Stafford Smith, M. (1991). Risk, biology and drought management strategies for cattle in central Australia. Environmental Management 33, 17-33.

Gillard, P. (1979). Improvement of native pastures with Townsville stylo in the dry tropics of sub-coastal northern Queensland. Australian Journal of Experimental Animal Husbandry 19, 325-336. doi:10.1071/ EA9790325

Gillard, P., and Moneypenny, R. (1988). Decision support approach for the beef industry of tropical Australia. Agricultural Systems 26, 179-190. doi:10.1016/0308-521X(88)90010-8 
MacLeod, N. D., and Ash, A. A. (2001). 'Development of a Spreadsheet Herd Dynamics Model to Assess the Economic Value of Forecasts in Extensive Grazing Enterprises.' Oceans to Farms Project Report No. 6. (CSIRO Sustainable Ecosystems: Brisbane and Townsville, Qld.)

MacLeod, N. D., and McIvor, J. G. (2004). An economic assessment of the impact of grazing land condition on livestock performance in tropical woodlands. The Rangeland Journal 26, 49-71. doi:10.1071/RJ04004

MacLeod, N. D., Scanlan, J. C., Whish, G. L., Pahl, L. I., and Cowley, R. A. (2011). Application of bio-economic simulation models for addressing sustainable land management issues for northern Australia. In: 'MODSIM2011, 19th International Congress on Modelling and Simulation'. (Eds F. Chan, D. Marinova and R. S. Anderssen.) pp. 800-807. (Modelling and Simulation Society of Australia and New Zealand: Canberra, ACT.) Available at: www.mssanz.org.au/ modsim2011/D10/wongsosaputro (accessed 25 March 2013).

Mayer, D. G., Scanlan, J. C., Cowley, R. A., Singh, D., and McKeon, G. M. (2011). Testing and calibrating empirical models of cattle growth on native pastures in northern Australia. In: 'MODSIM2011, 19th International Congress on Modelling and Simulation'. (Eds F. Chan, D. Marinova and R. S. Anderssen.) pp. 815-821. (Modelling and Simulation Society of Australia and New Zealand: Canberra, ACT.) Available at: www.mssanz.org.au/modsim2011/D10/wongsosaputro (accessed 25 March 2013).

Mayer, D. G., McKeon, G. M., and Moore, A. D. (2012). Prediction of mortality and conception rates of beef breeding cattle in northern Australia. Animal Production Science 52, 329-337. doi:10.1071/ AN11204

McKeon, G. M., Ash, A. J., Hall, W. B., and Stafford Smith, M. (2000). Simulation of grazing strategies for beef production in north-east Queensland. In: 'Applications of Seasonal Climate Forecasting in Agricultural and Natural Ecosystems - The Australian Experience'. (Eds G. Hammer, N. Nicholls and C. Mitchell.) pp. 227-252. (Kluwer Academic Press: Dordrecht, The Netherlands.)

McKeon, G. M., Stone, G. S., Syktus, J. I., Carter, J. O., Flood, N. R., Ahrens, D. G., Bruget, D. N., Chilcott, C. R., Cobon, D. H., Cowley, R. A., Crimp, S. J., Fraser, G. W., Howden, S. M., Johnston, P. W., Ryan, J. G., Stokes, C. J., and Day, K. A. (2009). Climate change impacts on northern Australian rangeland livestock capacity: a review of issues. The Rangeland Journal 31, 1-29. doi:10.1071/RJ08068

O'Reagain, P. J., and Scanlan, J. C. (2013). Sustainable management for rangelands in a variable climate: evidence and insights from northern Australia. Animal 7, 68-78. doi:10.1017/S175173111100262X
O'Reagain, P. J., and Turner, J. R. (1992). An evaluation of the empirical basis for grazing management recommendations for rangeland in southern Africa. Journal of the Grassland Society of Southern Africa 9 , 38-49. doi:10.1080/02566702.1992.9648297

O'Reagain, P. J., Bushell, J. J., Holloway, C. H., and Reid, A. (2009). Managing for rainfall variability: effect of grazing strategy on cattle production in a dry tropical savanna. Animal Production Science 49, 85-99. doi:10.1071/EA07187

O'Reagain, P., Bushell, J., and Holmes, W. (2011). Managing for rainfall variability: long-term profitability of different grazing strategies in a northern Australian tropical savanna. Animal Production Science 51, 210-224. doi:10.1071/AN10106

Pahl, L. I., Whish, G. L., MacLeod, N. D., Scanlan, J. C., and Cowley, R. A. (2011). Improved pasture management can improve profitability and resilience to climate change in northern Australia. In: 'MODSIM2011, 19th International Congress on Modelling and Simulation'. (Eds F. Chan, D. Marinova and R. S. Anderssen.) pp. 836-842. (Modelling and Simulation Society of Australia and New Zealand: Canberra, ACT.) Available at: www.mssanz.org.au/ modsim2011/D10/wongsosaputro (accessed 25 March 2013).

Scanlan, J. C., Cowley, R. A., McKeon, G. M., Clewett, J., Fraser, G., Materne, C. M., and Pettit, C. L. (2008). 'Methods for Calibrating GRASP from the Literature and Field Data. Appendix 14: Improving Grazing Management using the GRASP Model.' (Meat \& Livestock Australia Limited: Sydney.)

Scanlan, J. C., Whish, G. L., Pahl, L. I., Cowley, R. A., and MacLeod, N. D. (2011). Assessing the impact of pasture resting on pasture condition in the extensive grazing lands of northern Australia. In: 'MODSIM2011, 19th International Congress on Modelling and Simulation'. (Eds F. Chan, D. Marinova and R. S. Anderssen.) pp. 877-883. (Modelling and Simulation Society of Australia and New Zealand: Canberra, ACT.) Available at: www.mssanz.org.au/ modsim2011/D10/wongsosaputro (accessed 25 March 2013).

Scattini, W. J. (1973). A model for beef cattle production from rangeland and sown pasture in south-eastern Queensland Australia. PhD Thesis, University of California, Berkeley, CA, USA.

Tothill, J. C., McDonald, C. K., Jones, R. M., and Hargreaves, J. N. G. (1992). 'BOTANAL: A Comprehensive Sampling Procedure for Estimating Pasture Yield and Composition. Field Sampling.' Tropical Agronomy Technical Memorandum. (CSIRO Division of Tropical Crops and Pastures: Brisbane.) 